\title{
Surto de listeriose sistêmica em chinchilas
}

\author{
Outbreak of systemic listeriosis in chinchillas
}

\author{
Jackeline Karsten Kirinus ${ }^{\mathrm{I}}$ Carina Krewer ${ }^{\mathrm{I}}$ Diego Zeni ${ }^{\mathrm{I}}$ Fernanda Monego ${ }^{\mathrm{I}}$ \\ Marcia Cristina da Silva ${ }^{\text {II }}$ Glaucia Denise Kommers ${ }^{\text {II }}$ Agueda Castagna de Vargas ${ }^{{ }^{*}}$
}

\section{- NOTA-}

\section{RESUMO}

A listeriose é uma doença infecciosa que afeta uma grande variedade de espécies animais, causando septicemia, encefalite e aborto. As chinchilas são os animais mais susceptíveis à infecção sistêmica por Listeria monocytogenes. Este relato descreve um surto de listeriose sistêmica em uma criação de chinchilas da região central do Estado do Rio Grande do Sul, onde cerca de 16\% das chinchilas morreram. Na necropsia, havia múltiplos focos brancos, pequenos e de distribuição aleatória nas superfícies capsular e de corte do fígado e aumento de volume do linfonodo hepático. Histologicamente, observaram-se hepatite necrossupurativa e linfadenite supurativa multifocais, com numerosos bacilos intralesionais. L. monocytogenes foi o agente etiológico do surto de listeriose sistêmica, sendo o diagnóstico confirmado por meio das lesões de necropsia e histopatológicas, das características fenotípicas e genotípicas da bactéria e da técnica de imuno-histoquímica.

Palavras-chave: doenças de chinchilas, Listeria monocytogenes, bacteriologia, patologia.

\section{ABSTRACT}

Listeriosis is an infectious disease, which affects a variety of animal species and cause septicemia, encephalitis and abortion. Chinchillas are the most susceptible animals to the systemic infection by Listeria monocytogenes. This report describes an outbreak of systemic listeriosis in a farm of chinchillas in the Central region of the Rio Grande do Sul state, Brazil. Mortality rate was about $16 \%$. On necropsy, there were multiple random small white foci on the liver capsule and parenchyma and enlargement of the hepatic lymph node. Histologically, there were multifocal necro-suppurative hepatitis and suppurative lymphadenitis with numerous intralesional bacilli. L. monocytogenes was the etiology of the systemic listeriosis outbreak. The diagnosis was based on gross and microscopic lesions, genotypical and phenotypical characteristics and by immunohistochemistry technique.

Key words: diseases of chinchillas, Listeria monocytogenes, bacteriology, pathology.

Infecções por Listeria monocytogenes têm sido descritas em todo o mundo em uma ampla variedade de animais, incluindo bovinos, ovinos, caprinos, equinos, suínos, galinhas, chinchilas, coelhos, pássaros e peixes (CAVILL, 1967; DAVIES, 1984; MacDONALD et al., 1972; WATSON \& EVANS, 1985).

A listeriose pode manifestar-se na forma de três entidades clínicas distintas, sendo elas: infecção do útero grávido, resultando em aborto; e septicemia, com desenvolvimento de abscessos em vísceras e encefalite. Raramente essas três manifestações clínicas são vistas simultaneamente no mesmo animal (WILKERSON et al., 1997; KIMPE et al., 2004). A forma septicêmica (forma visceral) pode ocorrer com ou sem encefalite e afeta principalmente monogástricos, enquanto as formas encefálica e reprodutiva (aborto) ocorrem com maior frequência em ruminantes (WILKERSON et al., 1997).

'Laboratório de Bacteriologia, Universidade Federal de Santa Maria (UFSM), 97105-900, Santa Maria, RS, Brasil. E-mail: agueda.vargas@gmail.com.*Autor para correspondência.

IIPrograma de Pós-graduação em Medicina Veterinária, UFSM, Santa Maria, RS, Brasil. 
O gênero Listeria é formado por várias espécies, entretanto apenas duas espécies são consideradas patogênicas para animais, $\boldsymbol{L}$. monocytogenes e L. ivanovii (LOW \& DONACHIE, 1997; KIMPE et al., 2004). Chinchilas (Chinchilla lanigera) são consideradas uma das espécies mais susceptíveis à infecção sistêmica por $\boldsymbol{L}$. monocytogenes (WILKERSON et al., 1997; KIMPE et al., 2004), resultando em surtos com grande número de mortes (FINLEY \& LONG, 1977; DAVIES et al., 1984;). Um caso de infecção por $\boldsymbol{L}$. ivanovii foi descrito em uma chinchila na Bélgica (KIMPE et al., 2004).

Os casos de infecção sistêmica por $\boldsymbol{L}$. monocytogenes são agudos, e as chinchilas morrem entre 24 e 48 horas após a manifestação de sinais clínicos que geralmente são inespecíficos e incluem anorexia, emagrecimento, diarreia ou constipação. Algumas chinchilas podem morrer sem apresentar qualquer sinal clínico prévio (MACDONALD et al., 1972; FINLEY \& LONG 1977; WILKERSON etal., 1997).

Foram remetidas para necropsia três chinchilas provenientes de um criatório da região central do Rio Grande do Sul. O criatório consistia de
300 chinchilas em que 50 morreram (16,67\%) num período de duas semanas, sem apresentar sinais clínicos específicos. A maioria das chinchilas mortas eram fêmeas no estro e filhotes.

Das chinchilas necropsiadas, uma era macho jovem, e as outras eram fêmeas de dois anos. Macroscopicamente, as chinchilas estavam em bom estado corporal, e alterações foram vistas apenas no fígado (chinchilas 1-3) e no linfonodo hepático (chinchila 3). No fígado, havia numerosos focos (13mm de diâmetro) brancos distribuídos aleatoriamente por toda a superfície capsular (Figura 1A) e no parênquima. O linfonodo hepático estava moderadamente aumentado de volume. Histologicamente, os pontos brancos vistos no fígado correspondiam a áreas de inflamação necrossupurativa, com aglomerados de neutrófilos caracterizando microabscessos (Figura 1B) de distribuição aleatória. Havia também áreas de necrose de coagulação e agregados bacterianos basofílicos intralesionais. Linfadenite supurativa multifocal foi observada no linfonodo hepático.

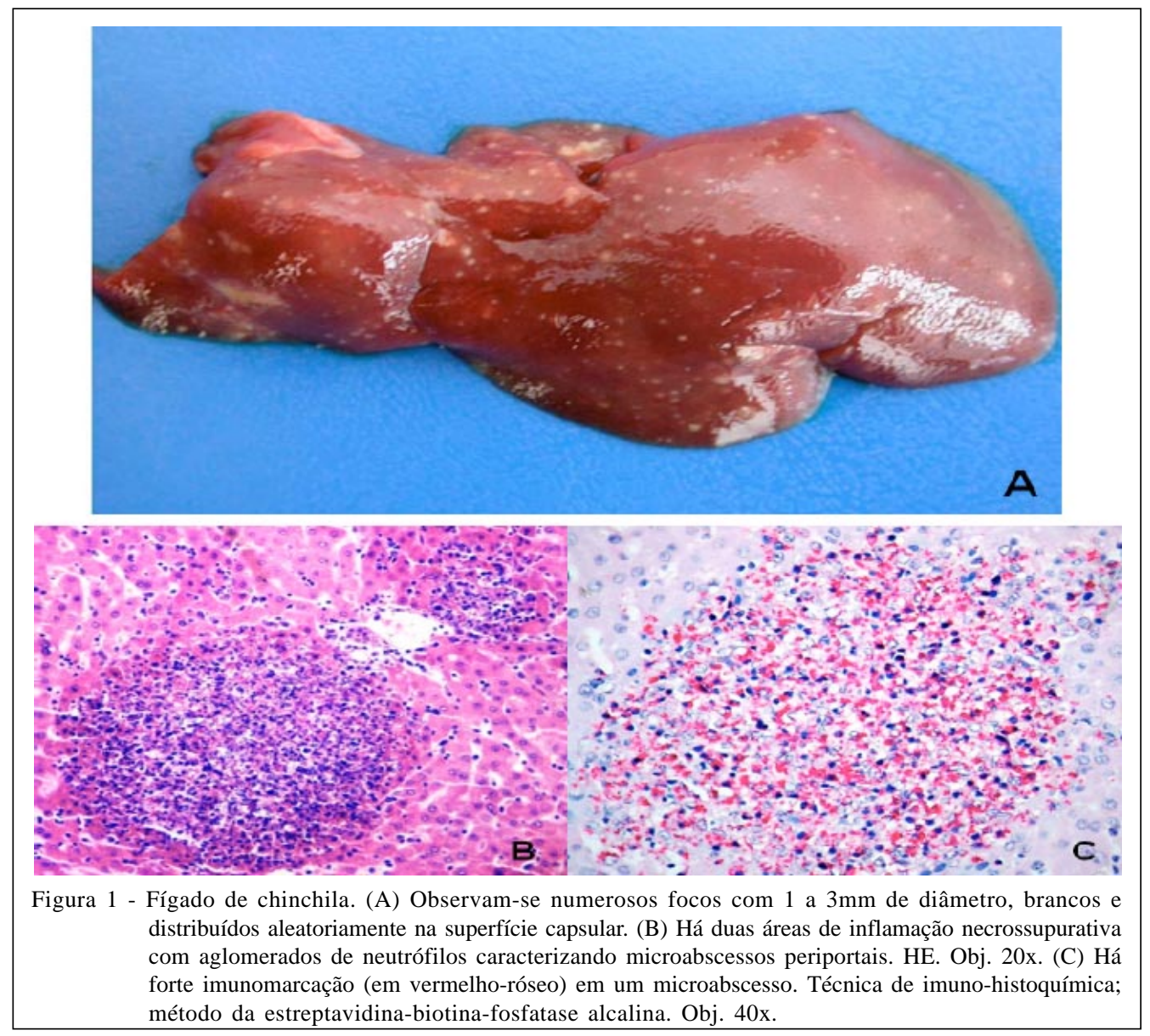

Ciência Rural, v.40, n.3, mar, 2010. 
Utilizou-se a técnica de imuno-histoquímica para detecção do agente nas lesões. Empregou-se o método da estreptavidina-biotina-fosfatase alcalina ${ }^{\mathrm{a}}$, sendo realizada a recuperação antigênica com TrisEDTA em pH 9,0, por 10 minutos, em forno de microondas. $\mathrm{O}$ anticorpo primário ${ }^{\mathrm{b}}$ policlonal produzido em coelho anti-Listeria monocytogenes, na diluição de 1:1000, foi incubado por 1 hora a $37^{\circ} \mathrm{C}$, adaptado de CAMPERO et al. (2002). Como substrato-cromógeno, utilizou-se Permanent Red ${ }^{a}$. Foi observada forte imunomarcação para L. monocytogenes, principalmente nos microabscessos (Figura 1C). Menos frequentemente observaram-se organismos individualizados livres no citoplasma de hepatócitos e de células de Kupffer.

Amostras de fígado, pulmão e intestino delgado de duas chinchilas necropsiadas foram encaminhadas para exame bacteriológico. As amostras foram semeadas em ágar sangue ovino a $5 \%$ e incubadas a $37^{\circ} \mathrm{C}$, por 48 horas. A identificação bacteriana foi realizada mediante características morfológicas, tintoriais, bioquímicas (QUINN et al., 1994) e moleculares dos isolados. Efetuou-se ainda o teste de susceptibilidade aos antimicrobianos pelo método de difusão em disco, segundo o NCCLS (1999).

Na cultura bacteriológica, verificaram-se colônias pequenas, translúcidas e hemolíticas, identificadas como bacilos gram-positivos. Os isolados foram submetidos à caracterização bioquímica, demonstrando motilidade, capacidade de fermentar a lactose, produzir catalase e $\mathrm{H}_{2} \mathrm{~S}$, além de realizar hidrólise da esculina. Não houve fermentação do manitol, nem a produção de urease e oxidase. A fermentação do manitol tem sido descrita como uma ferramenta bastante útil na diferenciação de isolados patogênicos e não patogênicos desse microrganismo (QUINN et al., 1994). O DNA bacteriano foi submetido à reação da polimerase em cadeia para amplificação do gene que codifica a região 16S do rRNA (FREDRICKS \& RELMAN, 1998). Os produtos de amplificação foram purificados com polietilenoglicol (PEG-8000) e submetidos ao sequenciamento de DNA, realizado em sequenciador automático MEGABACE 1000. Pela caracterização fenotípica, os isolados foram classificados como $\boldsymbol{L}$. monocytogenes, e o sequenciamento confirmou a identidade deste agente.

No teste de sensibilidade aos antimicrobianos, as amostras revelaram-se sensíveis à amoxicilina, à ampicilina, à enrofloxacina, à eritromicina e ao florfenicol e resistentes à estreptomicina, gentamicina, neomicina, rifampicina, sulfazotrim e tetracilina, o que está de acordo com HOF (1991), que relata experimentalmente a sensibilidade de $\boldsymbol{L}$. monocytogenes à ampicilina e amoxicilina. O perfil de sensibilidade aos antimicrobianos orientou a terapia, e alguns dos animais foram tratados com enrofloxacina, auxiliando no controle do surto.

A listeriose é uma das principais doenças de chinchilas, e as mortes causadas pelos surtos da doença foram responsáveis por perdas econômicas no comércio de peles de chinchilas por todo o mundo (CAVILL, 1967; FINLEY \& LONG, 1977).

No surto aqui descrito, antes do início das mortes, a dieta das chinchilas havia sido alterada. Apesar de não terem sido realizados testes bacteriológicos na dieta introduzida, que poderiam indicar uma possível fonte de contaminação, evidências circunstanciais sugerem que neste surto a fonte de contaminação tenha sido alimentar. É sabido que $\boldsymbol{L}$. monocytogenes tem grande habilidade em sobreviver e se multiplicar em diferentes ambientes, proporcionando um número elevado de rotas de transmissão da infecção (IVANEK et al., 2007). Alguns autores citam que a alimentação e a presença de outros animais infectados podem ter relação com a contaminação (FINLEY \& LONG, 1977). Alimentos contaminados com fezes de roedores, aves ou ruminantes têm sido descritos em surtos de listeriose em chinchilas (WILKERSON et al., 1997).

As recomendações para quebrar o ciclo de transmissão oral incluem remoção do alimento que pode estar contaminado, eutanásia dos animais em estágio terminal da doença e desinfecção de gaiolas e bebedouros (WILKERSON et al., 1997). No criatório, foram adotados como métodos de controle a desinfecção do ambiente e a substituição da ração e da água. A partir desses procedimentos, não foram mais relatados novos casos de infecção.

Neste surto, o diagnóstico de listeriose septicêmica fundamentou-se nos aspectos epidemiológicos e nos achados patológicos e bacteriológicos. Portanto, considerou-se oportuno divulgar este surto para que os profissionais que trabalham com animais de produção conheçam as características da doença, os métodos diagnósticos empregados na sua identificação e as medidas de controle da enfermidade.

\section{FONTES DE AQUISIÇÃO}

a - Dako Cytomation (Carpinteria, CA, EUA).

b - BD/Difco, (Sparks, MD, EUA).

\section{REFERÊNCIAS}

CAMPERO, C.M. et al. Demonstration of Listeria monocytogenes by immunohistochemistry in formalin-fixed brain tissues from natural cases of ovine and bovine encephalitis.

Ciência Rural, v.40, n.3, mar, 2010. 
Journal of Veterinary Medicine B, v.49, p.379-383, 2002. Disponível em: <http://www3.interscience.wiley.com/cgi-bin/ fulltext/118955335/PDFSTART.> Acesso em: 5 ago. 2009. doi: 10.1046/j.1439-0450.2002.00586.

CAVILL, J.P. Listeriosis in chinchillas (Chinchilla laniger). Veterinary Record, v.80, n.20, p.592-594, 1967.

DAVIES, J.W. et al. Listeria monocytogenes infections in Canada. Clinical Investigation Medical, v.7, n.4, p.315320, 1984. Disponível em: <http://www.ncbi.nlm.nih.gov/pmc/ articles/PMC1946778>. Acesso em: 5 jul. 2009.

FINLEY, G.G.; LONG, J.R. An epizootic of listeriosis in chinchillas. Canadian Veterinary Journal, v.18, n.6, p.164167, 1977. Disponível em: <http://www.ncbi.nlm.nih.gov/pmc/ articles/PMC1697592/pdf/canvetj00379-0046.pdf/ ?tool=pmcentrez $>$. Acesso em: 7 ago. 2009

FREDRICKS, D.N.; RELMAN, D.A. Improved amplification of microbial DNA from blood cultures by removal of the PCR inhibitor sodium polyanetholesulfonate. Journal Clinical Microbiology, v.36, n.10, p.2810-2816, 1998. Disponível em: <http://www.ncbi.nlm.nih.gov/pubmed/9738025>. Acesso em: 26 jun. 2009.

HOF, H. Therapeutic activities of antibiotics in listeriosis. Infection, v.19, p.5229-5233, 1991. Disponível em: <http:/ /www.scopus.com/record/display.url?eid=2-s2.0$0025906132 \&$ vi e w $=$ ba sic \& origi n = in wa d\&txGid=1yCXByjiARqC_Eoqi_7qdqH\%3a2.> Acesso em: 20 ago. 2009.

IVANEK, R. et al. Markov chain approach to analyze the dynamics of pathogen fecal shedding-example of Listeria monocytogenes shedding in a herd of dairy cattle. Journal of Theoretical Biology, v.245, n.1, p.44-58, 2007. Disponível em: <http://www.sciencedirect.com/ science?_ob=ArticleURL\&_udi=B6WMD-4M2GGXT- 18_user=687358\&_rdoc $=18 \_f m t=8 \_o r i g=$ search\&_sort $=$ d\&_docan chor $=\&$ view $=$ c \&_acct $=C 000037899 \&$ version $=1 \&$ \& urlVersio $\mathrm{n}=0$ \&_userid=687358\&md5=333f1d1a2d377aac9ec2d25f81b145c3>. Acesso em: 18 ago. 2009. doi: 10.1016/j.jtbi.2006.09.031.

KIMPE, A. et al. Isolation of Listeria ivanovii from a septicaemic chinchilla (Chinchilla lanigera). Veterinary Record, n.154, p.791-792, 2004

LOW, J.C.; DONACHIE, W. A review of Listeria monocytogenes and listeriosis. Veterinary Journal, n.153, p.9-29, 1997. Disponível em: <http://www.ncbi.nlm.nih.gov/pubmed/ 9125353>. Acesso em: 27 jul. 2009. doi: 10.1016/s10900233(97)80005-6.

MacDONALD, D.W. et al. Listeria monocytogenes isolations in Alberta 1951-1970. Canadian Veterinary Journal, v.13, n.3, p.69-71, 1972. Disponível em: <http://www.ncbi.nlm.nih.gov/ pmc/articles/PMC1695638>. Acesso em: 17 jun. 2009.

NATIONAL COMMITTEE FOR CLINICAL LABORATORY STANDARTS (NCCLS). Performance standards for antimicrobial susceptibility testing: Nineth Informational Supplement M100-S9. Wayne : PA, USA, 1999. V.19, n.1.

QUINN, P.J. et al. Clinical veterinary microbiology. Spain: Wolfe, 1994. 172p.

WATSON, G.L.; EVANS, M.G. Listeriosis in a rabbit. Veterinary Pathology, n.22, p.191-193, 1985. Disponível em: <http:// www.ncbi.nlm.nih.gov/pubmed/3920811 ?dopt=Abstract $>$. Acesso em: 23 ago. 2009.

WILKERSON, M.J. et al. An outbreak of listeriosis in a breeding colony of chinchillas. Journal of Veterinary Diagnostic Investigation, n.9, p.320-323, 1997. Disponível em: <http:/ /www.jvdi.org/cgi/reprint/9/3/320>. Acesso em: 7 ago. 2009. 